\title{
How do supervisee's learn during supervision? A Grounded Theory study of the perceived developmental process
}

\author{
Lynne H. Johnston ${ }^{{ }^{*}}$ and Derek L. Milne ${ }^{2}$ \\ ${ }^{1}$ Halley Johnston Associates Ltd, Tyne \& Wear, UK \\ ${ }^{2}$ School of Psychology, Ridley Building, Newcastle University, Newcastle upon Tyne, UK
}

Received 14 May 2011; Accepted 6 February 2012; First published online 16 March 2012

\begin{abstract}
To contribute to a model of CBT supervision, we interpreted supervisees' understanding of the processes involved in their receipt of supervision. Second, we assessed the utility of a Grounded Theory Methodology (GTM) to study supervision. Supervisees were interviewed about their experiences of supervision, within a cross-sectional, qualitative design. In-depth, face-to-face individual interviews were conducted with seven trainee clinical psychologists. Their perceptions of supervision were analysed by means of a constructivist revision of GTM. A conceptual model is presented, to show the learning process from the perspective of the supervisees. This suggests that the receipt of supervision was experienced against a developmental backdrop involving a progression along two continua: competency and awareness. A set of core processes (Reflection, Socratic Information Exchange, Scaffolding, Supervisory Alliance) were thought to interact, enabling appropriate learning across developmental stages. This was thought to facilitate movement through individualized Zones of Proximal Development (ZPD). The fidelity construct of 'receipt' is complex and does not lend itself to quantification and measurement using a positivistic approach. By contrast, GTM was a useful methodology to use in this context. Further research using a similar methodology may further contribute to a model of CBT supervision.
\end{abstract}

Key words: CBT supervision model, Clinical supervision, Grounded Theory.

\section{Introduction}

Supervision in cognitive-behavioural therapy (CBT) has largely been based on 'the same processes and methods that characterize the therapy', such as goal-setting, collaboration, and guided discovery (Padesky, 1996, p. 289). This affords supervisors a clear and internally consistent (reflexive) guide to supervision, one that is also associated with high levels of supervisee satisfaction (Townend et al. 2002). But, like supervision in general, CBT supervision lacks adequate conceptualization (Ellis et al. 1996). This pragmatic reliance on reflexivity restricts our ability to organize data, understand phenomena, make decisions,

\footnotetext{
*Author for correspondence: L. H. Johnston, Principal Psychologist, Sunderland Royal Hospital, City Hospitals Sunderland NHS Foundation Trust, Sunderland SR4 7TP, UK. (email: lynnejohnston@ halleyjohnstonassociates. co.uk)
} 
adapt interventions, train supervisors, conduct research, etc. (Bernard \& Goodyear, 2004). In short, 'without theory or a conceptual model, one does not really understand the process of supervision' (Hart, 1982, p. 27).

What is therefore required is a specific model for CBT supervision, in the same way that Bennett-Levy (2006) has proposed a CBT model for therapist skill development, the 'declarative-procedural-reflective' model (DPR), to address what he referred to as a 'theoretical vacuum' (p. 58). A sound model is comprehensive, drawing on a wide range of relevant data. By contrast, CBT supervision has been criticized as limited, in terms of ignoring potentially valuable ideas from parallel literatures for being purely reflexive (Milne, 2007, 2008). For example, it 'neglects ... modern educational theory' (Pretorius, 2006, p. 418). Additionally, a sound model is precise, removing vagueness or ambiguity. But CBT supervision has failed to detail the micro-skills of CBT supervision (James et al. 2008), such as 'scaffolding' and 'responsivity'. A further, related criterion is 'operationality', i.e. that a model should be specified in measurable terms - Popper's (1972) 'falsifiability' criterion. Until recently, there was no psychometrically valid, published instrument specifically designed to evaluate the CBT supervisor's competence (Milne et al. 2011). Without an instrument of this kind, it is impossible to falsify any assumptions made about CBT supervision. As detailed above, these conceptual weaknesses create numerous practical problems for CBT supervisors.

To begin to fill this vacuum, some work has been done on developing a sound model of CBT supervision. Just as Bennett-Levy (2006) drew on general theory to create his model of therapist skill acquisition (i.e. information-processing theory), so James et al. (2006) drew on expert consensus to piece together an integrative model drawing on seven inter-linked concepts, such as the 'zone of proximal development' (Vygotsky, 1978) and the theory of experiential learning (Kolb, 1984). This theoretical review by James et al. (2006), has been complemented by a systematic review of the best-available evidence, designed to construct inductively a basic supervision model (Milne et al. 2008). This clarified the moderators, mediators and mechanisms of effective supervision, offering support for the James et al. (2006) model. For example, $82 \%$ of the mechanisms reported in the sampled empirical studies (mostly CBT) were consistent with Kolb's (1984) theory of experiential learning. A further part of the theoretical jigsaw has been generated by experienced CBT therapists, who contributed their perceptions of what was effective in the development of CBT skills within training and supervision (Bennett-Levy et al. 2009). According to their sample of 120 therapists, a combination of educational methods was required to enable skill acquisition to occur, especially modelling and role-play. This is consistent with the foregoing, although Bennett-Levy et al. (2009) organized these therapists' perceptions within the DPR model. Similarly, an expert consensus has helped to define the general and CBT-specific competences (Roth \& Pilling, 2008).

Explicit attempts to model CBT supervision have included at least two studies utilising the qualitative method of Grounded Theory (GT; Glaser \& Strauss, 1967). In the first of these, Milne et al. (2003) studied 10 video tapes of CBT supervision within an informal GT approach, noting 14 themes (e.g. collaboration and conceptualization), mapping closely onto the Cognitive Therapy Scale - Revised (Blackburn et al. 2001). In a more recent, formal GT analysis, Townend (2008) interviewed 16 programme directors of CBT training courses in the UK, asking for their beliefs about what made their own supervision effective and appropriate. Eight themes were extracted from these interviews, including moderating factors 
(e.g. organizational structure), cognitive processes (e.g. reflection and self-awareness), and supervisory skills (e.g. using techniques to develop clinical skills, such as educational roleplay). Echoing the reflexive approach, Townend (2008, p. 9) noted that these skills 'were the same as those at the heart of cognitive behavioural psychotherapy', like goal-setting and guided discovery. In summary, these two GT studies indicated that CBT supervision consisted of multiple factors, ones that interacted in a dynamic way to foster the supervisee's development.

\section{Conceptual and methodological justification}

In the absence of a specific model for CBT supervision, Milne (2006) suggested drawing parallels between processes-outcome relationships in supervision and in therapy. One comparatively recent development within the therapy literature is the concept of treatment fidelity (e.g. Bellg et al. 2004; Resnick et al. 2005). Given that clinical supervision has itself been conceptualized as an intervention (Wampold \& Holloway, 1997), an original and yet logical development is therefore to examine the applicability of fidelity components in supervision. Johnston et al. (2009) have emphasized intervention fidelity testing as a key methodological requirement in applied psychology interventions, while Culloty et al. (2010) have illustrated its quantitative application within supervisor training. A first step in developing a rich qualitative understanding of each fidelity component, within the context of clinical supervision, is to explore and define each element from a variety of perspectives. The current study focuses on one component (receipt) and is restricted to one perspective (finalyear trainee psychologist). Following Bellg et al. (2004), receipt is defined as the supervisee's learning during supervision (i.e. the mini-impacts or immediate outcomes of supervision, such as improved understanding of a patient's presenting problem). This can be distinguished from what the supervisor may be doing to facilitate that learning (termed 'training', such as reformulating a case); and with any subsequent transfer of the learning ('enactment' or generalization, such as drawing on this reformulation at the next session).

The majority of clinical psychology supervision research has adopted an objectivist standpoint (e.g. Watkins, 1997), carrying various conceptual and methodological limitations (e.g. Ellis et al. 1996). It may be more productive to also study supervision from a constructionist stance (Charmaz, 2006). This standpoint may help to clarify whether clinical supervision is the dynamic, complex, interpersonal process some believe it to be (Holloway, 1984; Holloway \& Neufeldt, 1995; Wampold \& Holloway, 1997). Several theoretical perspectives are linked to a constructionist epistemology (see Denzin \& Lincoln, 2008). The perspective which informed the current study is interpretivism (Schwandt, 2003). The principle investigator (PI) was critically engaged in the receipt of her own clinical supervision. Thus, the co-construction of knowledge was grounded in the experiences of both the subject and object. Grounded Theory Methodology (GTM; Charmaz, 2006) was considered an appropriate approach, due to the focus on process factors (Richards \& Morse, 2007).

\section{Aim and objectives}

The aim of this study was to conceptualize, from the perspective of the supervisee, the receipt of clinical supervision. This was divided into two objectives: 
- To interpret supervisees' understanding of the processes involved in the receipt of supervision.

- To assess the utility of a Grounded Theory Methodology (GTM) to study the receipt of supervision.

The central research question was: "What are the key processes involved in the receipt of clinical supervision, as defined through GTM'? In terms of novelty, the present study builds on the two identified GTM studies of CBT supervision, as noted above, by drawing on the first author's position as a supervisee (i.e. peer of the participants) and as an experienced qualitative researcher; by contrasting several supervision approaches (CBT; psychodynamic, etc.); by the use of the best-available software to facilitate interview coding; and by adhering to robust quality criteria governing the methodology (Johnston et al. 1999, 2009).

\section{Method}

\section{Design}

Supervisees were interviewed about their experiences of supervision within a cross-sectional, qualitative design. At the time of the interview they had received supervision within four consecutive placements over a continuous 2-year period. This supervision reflected their supervisors' theoretical orientations, with the majority using a CBT approach (i.e. either pure CBT or 'eclectic' supervision), but there were also psychodynamic, systemic, cognitiveanalytic and eclectic supervisors (see Table 1 for details).

\section{Sampling strategy}

In line with GTM, an iterative approach to data collection and analysis was followed (see Fig. 1).

Participants were purposively sampled (Coyne, 1997) from the final year of a doctorate course in clinical psychology from a UK university. This was to ensure that the receipt phenomenon would be present in the sample. Theoretical sampling (Coyne, 1997) was then employed, based on the emergent thematic information.

\section{Data collection methods}

Ethical approval was gained from both the local NHS Trust and the host university. All participants signed a voluntary informed consent form and agreed to take part in one face-toface interview. Participants $(n=7)$ were all female, their mean age was 26.71 years (S.D. $=$ 2.06 years), and they had received supervision from a minimum of four clinical supervisors (see Table 1).

\section{Data management and analysis}

All interviews were digitally recorded using an Olympus WS-321M digital voice recorder. The data comprised $470.46(\chi=67.21$, S.D. $=6.86)$ minutes of digital recordings. Each recording was reviewed at least three times prior to each subsequent interview. This allowed 


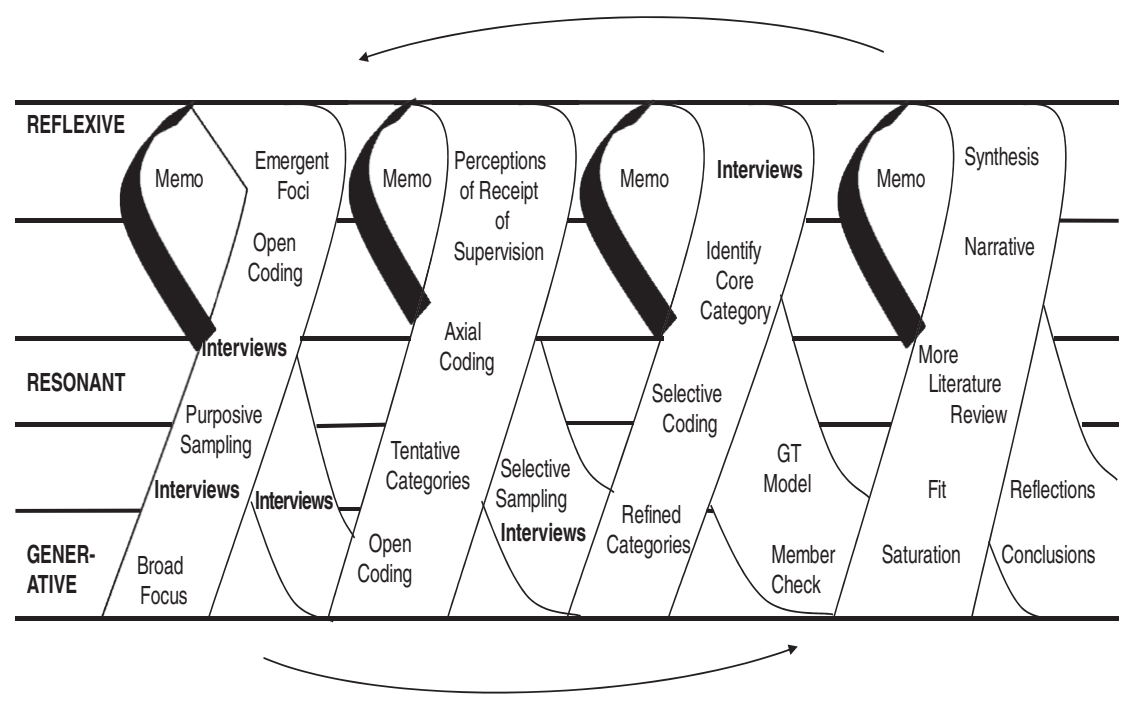

Fig. 1. The iterative process of data collection and analysis in Grounded Theory Methodology (adapted from Johnston et al. 1999, p. 268).

modifications to the interview guide to be made in accordance with GTM. All interviews were transcribed verbatim and transcripts were returned to each participant to check for accuracy. This resulted in $66657(\chi=9522$, S.D. $=1341)$ text-based words for analysis. The software programme QSR-NVIVO version 8 (QSR International, 2009) was used to manage and organize the data and to facilitate the analytical process (Hutchison et al. 2010). All digital interviews were imported into NVIVO8 with the accompanying verbatim transcripts. This helped to identify multiple levels of meaning (i.e. use of humour, sarcasm) as well as times where participants emphasized particular points (i.e. tone, pitch of voice).

The interpretation of the data involved the constant comparative method (Charmaz, 2006). This involved generating initial Free Nodes in NVIVO8 and using the Coding Stripes function to aid the comparative process. Each Node had a unique name, description and memo attached. As the analysis progressed, additional Free Nodes $(n=57)$ were created and further Memo writing undertaken. The Memo content moved from a descriptive summary, with reflective questions, to a broader conceptual development of the node and its relationship to other nodes. The extensive use of See Also Links enabled the integration of the secondary literature within memos (Hutchison et al. 2010). This included online articles (i.e. PDFs) and reading notes from book chapters and offline articles, which were recorded as Externals within NVIVO8 (see Fig. 2).

As the analysis process developed, the Modeler tool was utilized to dimensionalize the data and visually represent potential relationships and sub-categories. Tree Nodes were used to represent axial coding (fracturing the data into properties and dimensions). As the central themes became clearer, selective coding focused on making specific comparisons. This involved examining Coding Stripes to identify potential relationships, and then using the Query tool to ask specific questions (see Fig. 3). The end of a GTM journey is marked by theoretical saturation (Charmaz, 2006). Theoretical memos and models provided a clear audit 
Table 1. Participant's age and supervision experience at time of interview

\begin{tabular}{|c|c|c|c|c|c|c|}
\hline Part & $\begin{array}{l}\text { Age } \\
(\mathrm{yr})\end{array}$ & $\begin{array}{l}\text { Details of assistant } \\
\text { psychology posts }\end{array}$ & Supervisor details (first placement) & $\begin{array}{l}\text { Supervisor details } \\
\text { (second placement) }\end{array}$ & $\begin{array}{l}\text { Supervisor details (third } \\
\text { placement) }\end{array}$ & $\begin{array}{l}\text { Supervisor details (fourth } \\
\text { placement) }\end{array}$ \\
\hline 1 & 29 & $\begin{array}{l}\text { No assistant experience } \\
\text { but has experience in } \\
\text { research }\end{array}$ & $\begin{array}{l}\text { Adult } \\
\text { Focus: CBT } \\
\text { Female } \\
\text { Age: mid 30s } \\
\text { Grade: band } 8 \mathrm{~A} \\
\text { 1st trainee }\end{array}$ & $\begin{array}{l}\text { Child } \\
\text { Focus: systemic/CBT } \\
\text { Female } \\
\text { Age: early } 30 \text { s } \\
\text { Grade: band } 7 \\
\text { 1st trainee }\end{array}$ & $\begin{array}{l}\text { Older adult } \\
\text { Focus: eclectic } \\
\text { Female } \\
\text { Age: early } 30 \text { s. } \\
\text { Grade: band } 7 \\
\text { 1st trainee }\end{array}$ & $\begin{array}{l}\text { Learning disability } \\
\text { Focus: systemic } \\
\text { Female } \\
\text { Age: early 40s } \\
\text { Grade: band } 8 \mathrm{~B} \\
\text { 5+ trainees }\end{array}$ \\
\hline 2 & 28 & $\begin{array}{l}\text { Two posts. } \\
\text { Adult post: } \\
\text { Focus: CBT } \\
\text { CBT diploma } \\
\text { Female } \\
\text { Age: mid 40s } \\
\text { Grade: consultant } \\
\text { Experienced supervisor } \\
\text { Child post: } \\
\text { Focus: Post-qualified in } \\
\text { CBT, but worked } \\
\text { systemically, and } \\
\text { psychodynamically } \\
\text { Female } \\
\text { Age: mid 40s } \\
\text { Grade: consultant } \\
\text { Experienced supervisor }\end{array}$ & $\begin{array}{l}\text { Adult } \\
\text { Focus: CBT (some CAT) } \\
\text { Female } \\
\text { Age: mid 30s } \\
\text { CBT diploma } \\
\text { Lots of supervision experience of } \\
\text { trainees and those on CBT diploma }\end{array}$ & $\begin{array}{l}\text { Learning disability } \\
\text { Focus: eclectic } \\
\text { (CAT/systemic) } \\
\text { Female } \\
\text { Age: early } 30 \text { s } \\
2 \text { years post-qualified } \\
\text { 1st trainee }\end{array}$ & $\begin{array}{l}\text { Older adult } \\
\text { Focus: eclectic } \\
\text { Female, } \\
\text { Age: early } 30 \mathrm{~s} \\
\text { Approx. } 5 \text { years } \\
\text { post-qualified } \\
\text { Prior experience of } \\
\text { supervising trainees }\end{array}$ & $\begin{array}{l}\text { Child } \\
\text { Focus: psychodynamic } \\
\text { and systemic } \\
\text { Male } \\
\text { Age: mid 50s } \\
\text { Grade: consultant } \\
\text { Post-qualified as group } \\
\text { analyst } \\
\text { Lots of experience of } \\
\text { supervision }\end{array}$ \\
\hline 3 & 27 & $\begin{array}{l}\text { Three posts } \\
\text { 1. Forensic } \\
\text { Focus: CBT } \\
\text { Male } \\
\text { Age: mid } 20 \mathrm{~s} \\
\text { Trainee forensic } \\
\text { No supervised experience } \\
\text { 2. Forensic }\end{array}$ & $\begin{array}{l}\text { Learning disability } \\
\text { Focus: CBT } \\
\text { Female } \\
\text { Age: late } 30 \mathrm{~s} \\
\text { Grade: band } 8 \mathrm{~B} \text { supervised around } 10 \\
\text { trainees }\end{array}$ & $\begin{array}{l}\text { Adult } \\
\text { Focus: CBT } \\
\text { (dynamically informed) } \\
\text { Male } \\
\text { Age: early } 30 \text { s } \\
\text { Grade: band } 7 \\
\text { 1st trainee }\end{array}$ & $\begin{array}{l}\text { Older adult } \\
\text { Focus CBT } \\
\text { Male } \\
\text { Age: early } 40 \mathrm{~s} \\
\text { Grade: band } 8 \mathrm{~B} \\
\text { supervised around } 20 \\
\text { trainees }\end{array}$ & $\begin{array}{l}\text { Child } \\
\text { Focus: systemic/family } \\
\text { therapy } \\
\text { Male } \\
\text { Age: early } 30 \text { s } \\
\text { Grade: band } 7 \\
\text { supervised } 3 \\
\text { trainees }\end{array}$ \\
\hline
\end{tabular}

Focus: CBT

Female, 
Age: early $30 \mathrm{~s}$

Grade: band 8a

Supervised 6 before

3. Adult

Person-centred/CBT

Male

Age: mid 30s

Grade: band 8B

Consultant counselling

psychologist

Supervised 3

assistants/trainees

One post
Child
Focus: CBT
Female
Age: late $30 \mathrm{~s}$
Grade: band $8 \mathrm{C}$

Three posts
One: neuropsychology
assistant/research

assistant/research

assistant with a male
Adult (two supervisors)

First supervisor

Focus: CBT informed

Female

Age: early 40s

Grade: band $8 \mathrm{~A}$

Postgraduate diploma course in CBT

Approx. 8-10 years post-qualification

experience

Previous experience of supervision

Second supervisor

Focus: eclectic (CBT and

psychodynamic theories)

Female

Age: early 40s

Grade: band $8 \mathrm{~B}$

Approx. 8-10 years post-clinical

training

Greater depth of experience

(secondary services, forensic, child

protection)

Child

Focus: psychodynamic

Female

Age: mid 30s
Learning disability

Focus: CBT

Female

Age: mid 30s

Grade: band 8A

3-4 years

post-qualification

(1)
Older adults

Focus: CBT

Male

Age: early 50s

Grade: band 8C

(consultant and clinical

lead)

10-15 years

post-qualification
Child

Focus: psychodynamic

Female

Age: mid 30s

Grade: band 8A

5-6 years

post-qualification

Completed psychodynamic

training
Adult
Focus: CBT
Two supervisors
Male
Learning disability

Focus: eclectic

Female

Age: late 50s
Older adult

Focus: CBT

Female

Age: mid 30s 
Table 1 (cont.)

\begin{tabular}{|c|c|c|c|c|c|c|}
\hline Part & $\begin{array}{l}\text { Age } \\
(\mathrm{yr})\end{array}$ & $\begin{array}{l}\text { Details of assistant } \\
\text { psychology posts }\end{array}$ & Supervisor details (first placement) & $\begin{array}{l}\text { Supervisor details } \\
\text { (second placement) }\end{array}$ & $\begin{array}{l}\text { Supervisor details (third } \\
\text { placement) }\end{array}$ & $\begin{array}{l}\text { Supervisor details (fourth } \\
\text { placement) }\end{array}$ \\
\hline & & $\begin{array}{l}\text { consultant clinical } \\
\text { psychologist } \\
\text { Experienced supervisor } \\
\text { Age: late 50s } \\
\text { Two: forensic } \\
\text { Clinical psychologist } \\
\text { working towards } \\
\text { Consultant } \\
\text { Male } \\
\text { Age: late 30s } \\
\text { No previous supervisory } \\
\text { experience } \\
\text { Three: inpatient secure } \\
\text { unit } \\
\text { Female } \\
\text { Age: early 40s } \\
\text { Consultant clinical } \\
\text { psychologist } \\
\text { Experienced supervisor }\end{array}$ & $\begin{array}{l}\text { Qualified for } 5 \text { years } \\
\text { Previously trained as counselling } \\
\text { psychologist } \\
\text { Had supervised first-year trainees for } \\
\text { previous } 3 \text { years }\end{array}$ & $\begin{array}{l}\text { Age: mid } 30 \mathrm{~s} \\
\text { Qualified for } 5 \text { and } 7 \\
\text { years, respectively } \\
\text { First supervisor had not } \\
\text { supervised before } \\
\text { Second supervisor } \\
\text { supervised previously } \\
\text { and worked as } \\
\text { academic tutor on the } \\
\text { doctorate course }\end{array}$ & $\begin{array}{l}\text { Grade: consultant and } \\
\text { clinical lead for MDT } \\
\text { Experienced supervisor }\end{array}$ & $\begin{array}{l}\text { Qualified } 10 \text { years } \\
\text { Supervised for past } 6 \text { years }\end{array}$ \\
\hline 6 & 25 & $\begin{array}{l}\text { One split post } \\
\text { Learning disability } \\
\text { Community setting } \\
\text { Focus: eclectic } \\
\text { Male } \\
\text { Age: early 50s } \\
\text { Grade: band } 8 \mathrm{~B} \\
\text { Supervised several } \\
\text { assistants before } \\
\text { Learning disability } \\
\text { In-patient setting } \\
\text { Focus: CBT } \\
\text { Male } \\
\text { Age: mid } 40 \mathrm{~s}\end{array}$ & $\begin{array}{l}\text { Learning disability } \\
\text { Focus: CBT/systemic female } \\
\text { Age: mid 40s } \\
\text { Grade: band } 8 \mathrm{~A} \\
\text { Supervised a few trainees }\end{array}$ & $\begin{array}{l}\text { Adult } \\
\text { Focus: psychodynamic } \\
\text { Male } \\
\text { Age: mid 40s } \\
\text { Grade: band } 8 \mathrm{~A} / 8 \mathrm{~B} ? \\
\text { Supervised several } \\
\text { trainees before }\end{array}$ & $\begin{array}{l}\text { Child } \\
\text { Focus: systemic } \\
\text { Male } \\
\text { Age: late } 30 \mathrm{~s} \\
\text { Grade: band } 8 \mathrm{~A} / 8 \mathrm{~B} ? \\
\text { Supervised a couple of } \\
\text { trainees before }\end{array}$ & $\begin{array}{l}\text { Older adult } \\
\text { Focus: CBT } \\
\text { Male } \\
\text { Age: early } 50 \mathrm{~s} \\
\text { Grade: band } 8 \mathrm{C} \\
\text { Supervised lots of trainees } \\
\text { before }\end{array}$ \\
\hline
\end{tabular}


Grade: band 8C/D

Head of service

Supervised several

trainees before

Two posts

Adult

Male

Age: early 40s

Grade: band $8 \mathrm{~B}$

Experienced clinician and

supervisor

Learning disability

Focus: systemic/CBT

Female

Age: late 20s

Grade: band 7

Recently qualified

supervisor

PI $39 \quad$ No assistant experience

but has expe
research

Adult

Focus: Systemic/CBT

Male

Age: early 40s

Grade: band 8A

Recently qualified supervisor (2nd

Adult (two supervisors)

First superviso

Focus: CBT

Female

Age: late 30s

Grade: band 8A/8B

Postgraduate diploma course in CBT

Approx. 10 years post-qualification

experience

Previous experience of supervision

Second supervisor

Focus: psychodynamic

Female

Age: early 30s

Grade: band 7

Approx. 2 years post-training

No previous supervision experience
Child

Focus: systemic/eclectic

Male

Age: mid 40s

Grade: band 8C

Very experienced

supervisor

Learning disability

Focus: eclectic

Psychodynamic/CAT

Female

Age: early 30s

Grade: band 7

Recently qualified

supervisor

1st trainee

Learning disability

Child

Focus: CBT

Female

Age: late 30s

Grade: band $8 \mathrm{~B}$

Supervised around 10

trainees

Focus: CAT

Female

Age: late $20 \mathrm{~s}$

Grade: band $8 \mathrm{~A}$

4 years

post-qualification.

No previous supervision

experience
Older adults

Focus: CAT

Female

Age: early 40s

Grade: band $8 \mathrm{~B}$

$10+$ years

post-qualification,

Approx. 7 years

supervisory experience. 


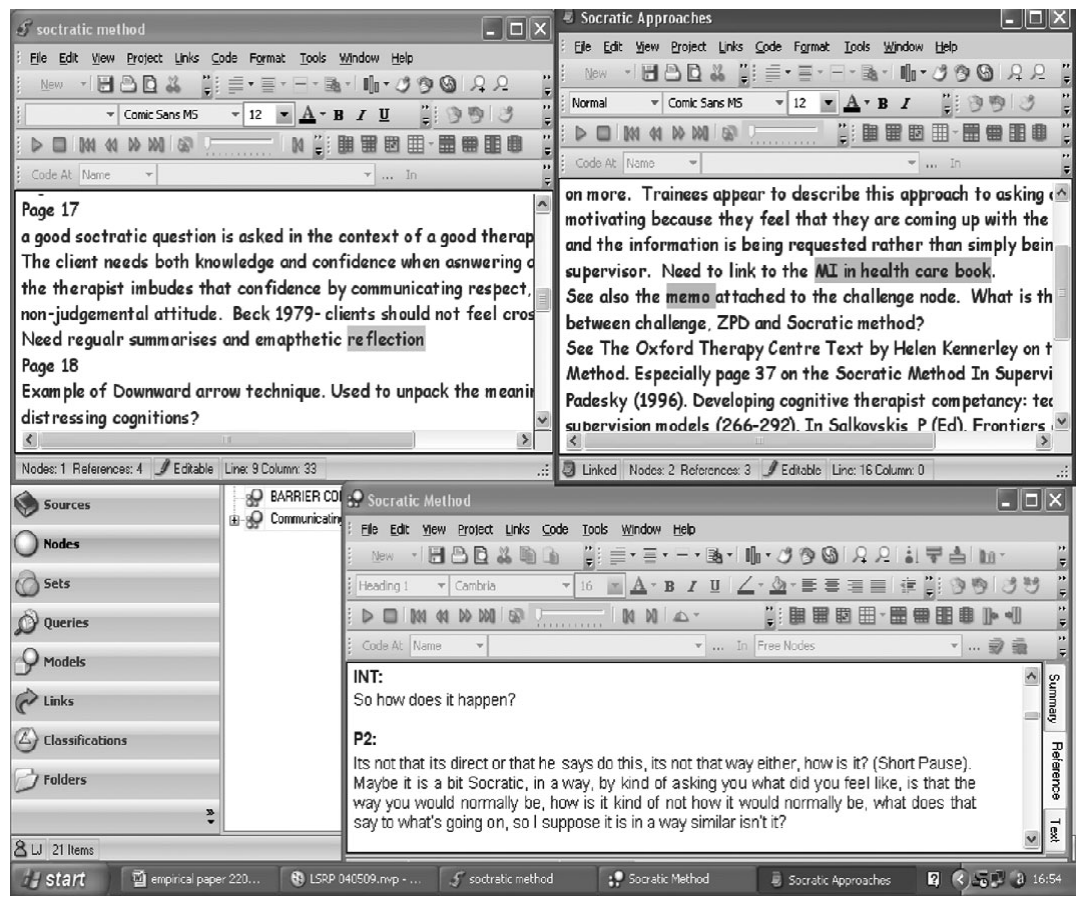

Fig. 2. NVIVO8 screen print showing the Socratic Method free node, memo and external.

trail of the analytical process and in documenting the decision to stop collecting further data after the seventh interview. The research diary was contained within NVIVO8; this acted as a conceptual management tool where data and literature were integrated. Critically, the research diary provided a clear record of prior assumptions, decisions made, procedures followed, questions (queries) asked, results found, and models built (see Bringer et al. 2004, 2007). The aforementioned methodological procedures diligently followed the approach outlined in previous published examples of the use of NVIVO software within a GTM (see Bringer et al. 2006a, b; Hutchison et al. 2010).

\section{Results}

Figure 4 shows receipt against a developmental backdrop (Contextual Background) progressing along two continua: Competency and Awareness. A set of core processes (Reflection, Socratic Information Exchange, Scaffolding, Supervisory Alliance) interact to enable appropriate processing of receipt across developmental stages. This facilitates movement through trainees' individualized Zones of Proximal Development (ZPD) from 'Blissful Ignorance' to 'Just do it'. Figure 4 cannot fully convey the complexity of the processes involved. Therefore, the following narrative illuminates these processes and quotations are used to exemplify key points. Relevant themes (NODES) are italicized in the Results section. 


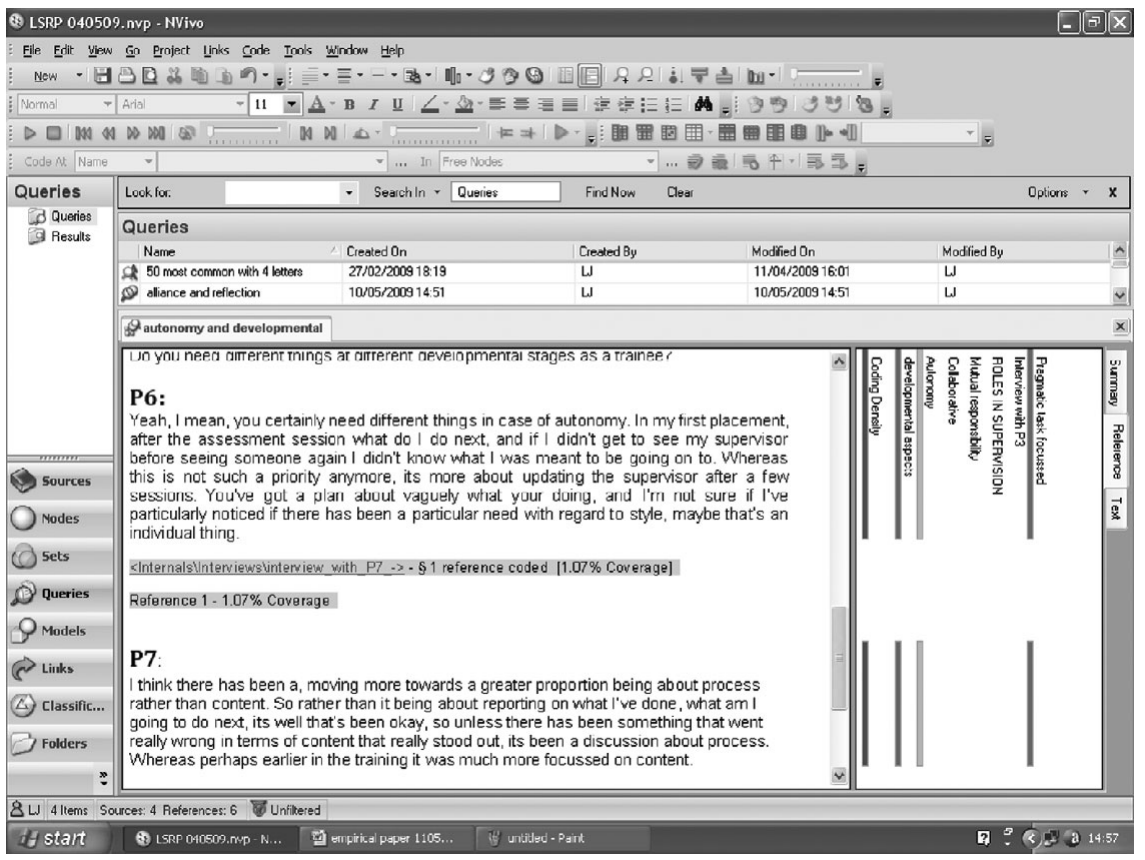

Fig. 3. NVIVO8 screen print showing the results node 'autonomy and developmental' with coding stripes.

\section{The importance of the supervisory alliance}

Trainees talked about the importance of the supervisory alliance throughout the developmental process. It was especially significant during earlier stages, where trainees reported that they would elicit a deeper level of supervision, if they were honest and open in their reflections about their clinical practice. Notably, trainees reported they were more able to do this when their supervisors also adopted an open, honest and inquisitive stance, because this facilitated the development of mutual trust and empathy:

I think, having someone else saying 'if I was working with them I'd find it hard', and you feel confident enough to open up say 'that was a nightmare session'. And then you take more from it; 'cos they can tell you more about it and then you've got more to go away with.

(Participant 2)

The supervisees reported that they were not open and honest about their needs when they perceived the supervisory alliance to be weak and/or when they feel unsafe. They felt unsafe when their supervisors were inconsistent and when feedback was either missing or communicated in an overly critical manner. Poor communication skills, personality factors and the imposition of an inflexible therapeutic style were all construed as factors which could damage the alliance. A weak alliance was perceived to be exacerbated by the inherent power differential associated with evaluation:

It's intrinsically quite a threatening process to go into; to be honest and open so that you can benefit, but doing that with the person that's your judge and executioner.

(Participant 5) 
1. 'Blissful Ignorance'

Supervisor Led. \& Training Focus (Didactic)

Procedural Reflective System

High Level of Teaching \& Scaffolding

Higher Levels of Anxiety

Need For Strong Alliance \& High Trust

Live or Video Observation Required

Pragmatic Task Focussed

Modelling of Supervisor

Limited Ability To Self Reflest Without scaffolding

Less Complex, Task Focussed, Case Specific.

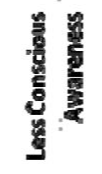

3. Goal Directed Attempts to 'Do it Right' Trainee Led Within ZPD Higher Levels of Anxiety Trainee Can Self Challenge Self Reflection On Action (e.g. Audio/Video) Trainee Can Seek Out Peer Supervision

\section{Les:} Competeney
2. 'Uncomfortable Recognition of Relative Incompetence' Supervisor Led

Higher Levels of Anxiety

Socratic Questions To Highlight training Needs (in ZPD)

Reflective Summaries To Make The Implicit Explicit.

Supervisor Elicits to Aid (\& Model) Reflection

Use of Self Reflection On Action (with lots of Scaffolding)

Strong Alliance \& High Trust Required

Credibility (Open \& Honest)

Initial Task Focussed But Increasing Awareness of IPP
Trainee Can Identify Guided Reading Need Supervisor to Elicit/Challenge As Per ZPD Increasing Awareness of IPP (Scaffolding Required) Scaffolding Required For More Complex Tasks

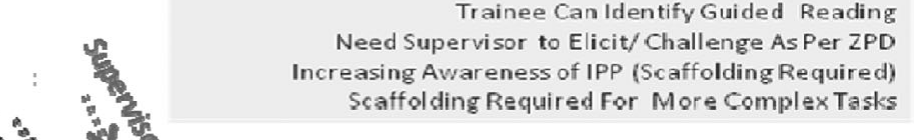

Zone's of Proxlmal Development

Declarative Knowledge System Collaborative Supervisory Alliance Joint Discovery Via Socratic Qs Much Less Teaching Or Scaffolding Lower Level of Anxiety Not Case Specific \& More Complexity More Attention To Dynamic Factors (IPP) Generalisable Knowledge \& Experience Potential For Reflection In Action As Well As On Action

Fig. 4. The developmental progression of the receipt of clinical supervision. 
Several factors influenced the development of a strong alliance. Trainees needed to feel there was a minimum level of mutual respect; agreement regarding a joint responsibility for the relationship, and clear roles. This facilitated a team approach which engendered mutual understanding, and shared goals and responsibilities. Several factors influenced the respect trainees had for their supervisors. Trainees expressed a clear preference to be supervised by clinicians who they perceived as professionally and personally credible. Personal credibility included a positive evaluation of supervisors' human qualities. This included being approachable, honest, warm, empathetic, and supervisee-centered. Professional credibility was discussed in terms of ability (i.e. as a supervisor, colleague and clinician). Critically, trainees emphasized the importance of having the opportunity to directly observe their supervisors work:

You're looking at these people to develop you, to show you, for instruction on how to do the job; and if those people can't do the job then 'how are you going to develop me into what I want to be?'

(Participant 3)

Trainees expressed a need for professional boundaries and expressed a preference for clearly delineated supervision time and space. Supervisors who were either unboundaried or excessively rigid were perceived as lacking in professional credibility. Further, trainees described high levels of anxiety and a need to put extra time, effort and energy into trying to understand such supervisors. Notably, in each case cited it was a supervisor who had imposed a psychodynamic model (inflexibly) onto trainees:

With this placement it has been very boundaried in the sense that you can contact me if there is risk, an emergency, but supervision is one hour, a regular time, and really that's supervision, and we will stop bang on the hour, regardless of whether I'm in mid-thought, mid-conversation ... the practical stuff I want to know, kind of sometimes gets left behind.

(Participant 4)

\section{A Socratic approach to information exchange and scaffolding}

In their earlier stages of training, trainees had less confidence, felt more anxious, needed more containment and less direct challenge. They wanted more practical and informational support and a greater amount of educational scaffolding. As they developed there was a movement away from discussions about specific skills and techniques (what to do) to a deeper collaborative discussion about inter-personal processes (how to do it). Trainees were able to look back on these earlier stages and understand their need for an increasing level of autonomy:

In my first placement, after the assessment session it was 'what do I do next?', and if I didn't get to see my supervisor before seeing someone again I didn't know what I was meant to be going on to. Whereas this isn't such a priority anymore, it's more about updating the supervisor after a few sessions.

(Participant 6)

A key pedagogic method discussed by all participants (irrespective of the supervisors' theoretical orientation) was the skilful use of Socratic dialogue. In earlier developmental stages trainees reported that the Socratic approach had a guiding or eliciting tone; in later stages the Socratic dialogue felt more collaborative. Socratic dialogue was perceived to be important for several reasons. First, to enable adequate time, space, and educational 
scaffolding; these helped trainees to remember and process information at a deeper level because the learning process was inherently more meaningful. Second, it had a clear impact on trainees' sense of ownership (i.e. they had made their own discoveries) and thus they were more motivated. Third it was viewed as a helpful way of regulating the trainees' emotions within their individualized ZPD. For example, when trainees felt appropriately anxious they were able to function well; when they were too anxious they were unable to process the information being 'transmitted'. The Socratic Method highlighted this and supervisors were able to respond and adapt accordingly.

When trainees answered questions but then received a lack of feedback this was not considered helpful or Socratic (although the supervisor may have believed they were being Socratic via their use of open questions). A compounding factor appeared to be that some supervisors failed to make things explicit. Thus, trainees were unable to 'know what they didn't know' or to be goal-directed in bringing what they knew into their awareness. Again the examples cited were all related to psychodynamic supervision:

If I hadn't have come with an agenda we would have sat in silence ... So I didn't receive information, I was actively told not to read books, 'cos that was my defence to get things right

... I do think that I learned a lot from the placement but I can't really tell you what I've learned!

(Participant 6)

\section{The centrality of the reflective process}

Trainees cited reflection as a key factor in aiding their receipt of supervision; however, this was not done in a structured, strategic, or active way:

Supervision will come back to me when I'm sitting thinking about a case formulation or I'm worried about a particular client, and I'm out walking the dog, and there will be that kind of flash of 'ooohhh' and it's like the pennies kind of been filtering through and reached a place where it makes sense and fits.

(Participant 5)

Nevertheless, reflection was enhanced when certain things were in place. First, the adoption of a Socratic approach with appropriate educational scaffolding facilitated their ability to understand and remember supervision because they felt more engaged in the process. Second, when trainees allowed themselves time and space immediately after their supervision session they were able to think about and process the material more effectively. Third, the emotional climate engendered within the supervisory alliance had a strong impact upon what was received and reflected upon. Trainee reflection appeared to depend on the way the information was transmitted, their ability (and willingness) to process and understand it, and the perceived salience (value judgment) attached to the information:

[CBT-based supervision] is not too infantilizing, or patronizing, it's about being collaborative, and helping you realize what you don't know; the Socratic questions and stuff like that. Whereas if it's someone who is psychodynamic and started trying to turn it into a weird therapy session. I would go along with for the [Doctoral] course but inside I'd be like, 'what are you going on about'!

(Participant 1)

Interestingly, while the use of audio or video recordings was perceived to be useful with clients, none of the supervisees recorded their supervision sessions and therefore they 
were highly reliant on their supervision notes. Supervisees' supervision notes changed developmentally in several ways. First, there was a movement from practical, task-focused (aide-mémoire) notes to notes about therapeutic processes. Second, notes became more focused and concise. Third, there was an increasing recognition of the need to allow adequate reflection time to write supervision notes. Fourth, in the later developmental stages there was increasing evidence of reflection taking place within supervision sessions, as well as afterwards. Interestingly, some trainees reported that they had been specifically told by psychodynamic supervisors not to take notes. This was not perceived as helpful.

\section{Discussion}

The current study supports and extends the literature detailing an emergent model of CBT supervision. As previously reported, we found that participants' perceived that carefully structured, collaborative, experiential work fostered their learning. Our findings also extend this small theoretical literature by emphasizing the view that the developmental context is integral to the receipt of clinical supervision (e.g. Watkins, 1997), and by illuminating the developmental process, especially the role of awareness in guiding experiential learning. All developmental models aim to demonstrate a progression from relative novice to accomplished therapist, and the most prominent is the Integrated Developmental Model (IDM) (Stoltenberg \& Delworth, 1987; Stoltenberg \& McNeil, 1997). In line with the IDM, the current work supports the idea that trainees are able to reflect upon a developing sense of self and others; and that they work with an increased level of autonomy as they move through their relative ZPD. The dimensions in Figure 4 were initially conceptualized across two dimensions representing a relative 'knowing' and 'not knowing' position. Green (2004) has also proposed this sequence of skill acquisition. The four quadrants depicted in Figure 4 represent movement across these developmental stages. Quadrants 1 and 4 are easy to differentiate because they lie at opposing ends of the process dimension (represented by the central spiral of movement through the trainees ZPD). However, Quadrants 2 and 3 are more difficult to differentiate and in accordance with IDM it may be that for different tasks trainees are relatively more or less aware of their relative incompetence. The following discussion offers an explanation as to why trainees' development may be dependent upon the complex interplay of four key constructs that allow movement to take place (Supervisory Alliance, Scaffolding, Socratic Information Exchange, Reflection).

\section{The supervisory alliance}

The importance of the supervisory alliance has been discussed by numerous authors (Bordin, 1983; Holloway, 1995; Worthen \& McNeil, 1996; Weaks, 2002; Beinart, 2004). The current study also emphasizes the centrality of the supervisory alliance; particularly in earlier developmental stages, to maximize the educative and restorative potential of supervision. The supervisees explained that without a strong alliance they held back on disclosures. Previous studies have noted a relationship between non-disclosure and a weak supervisory alliance (e.g. Webb \& Wheeler, 1998; Ladany \& Melincoff, 1999; Ladany et al. 1999). Further, Webb \& Wheeler (1998) found supervisees were less likely to make disclosures to supervisors who were imposed and those who held an assessment function. In the current 
study, constructs which were implicated in the development of a strong alliance were the supervisors' professional and personal credibility; the need for strong boundaries and clear roles; and the mutuality of the relationship. This supports existing research (e.g. Palomo et al. 2010).

Participants in the current study felt that the imposition of a psychodynamic model onto the supervisory dynamic had a negative impact upon the alliance. Their main complaints related to the inflexibility of the approach, rigid boundaries, and a lack of practical guidance. This was perceived to have impeded learning due to high levels of anxiety. This is somewhat at odds with psychoanalytical authors, who have emphasized the centrality of the alliance and the need to be supervisee-centred, open and safe (e.g. Dewald, 1997). One factor which may help to explain these differences is the use of explicit contracting at the beginning of the supervisory relationship (e.g. Scaife, 2001; Hawkins \& Shohet, 2007).

\section{Scaffolding and Socratic Method}

Trainees found the Socratic Method was beneficial because it was viewed as inherently supervisee-centred and developmentally sensitive. This appeared to aid their processing of receipt and ensured that the learning process was motivating. Learning in this way is likely to enhance self-efficacy (Bandura, 1997), positive affect and intrinsic motivation (Ryan \& Deci, 2000). Notably, the use of the Socratic Method is implicit within an approach to therapy which places the development of intrinsic motivation at its core: Motivational Interviewing (MI; Miller \& Rollnick, 1991, 2002). The relationship between the Socratic Method and educational scaffolding emerged as an important dynamic. This changed developmentally from task-focused scaffolding to process-focused scaffolding. Later stages were also associated with a more collaborative Socratic approach. Recently, James et al. (2008) highlighted the value of scaffolding as a key micro-skill within cognitive behavioural supervision. A similar level of micro-analysis has been pivotal to developments within MI and subsequent training initiatives (e.g. Amrhein et al. 2003, Amrhein, 2004). These types of micro-analytical studies are arguably much needed and are likely to yield useful practical teaching and supervision materials within clinical process research.

One question which emerges from the current study is why trainees perceived the receipt of supervision from psychodynamic supervisors to be non-Socratic and lacking in terms educational scaffolding and explicit feedback? Dewald (1997) offers an explanation in terms of differences in pedagogic theory within psychoanalytical supervision. While some psychoanalytical supervisors see feedback and encouragement as part of their role, others do not and espouse a position where 'judgments about what is good or bad are essentially reserved for quiet, silent reflection in the mind of the analyst or supervisor' (p. 38). Clearly trainees in the current study found this to be unhelpful and anxiety-provoking. Recent research within educational psychology would seriously question the rationale for minimal guidance and a lack of feedback (e.g. Kirschner et al. 2006).

\section{The role of reflection}

While reflection has been highlighted as a 'blind spot' within psychology (e.g. Bennett-Levy, 2006), its importance is recognized within the adult learning literature (e.g. Kolb, 1984; Boud et al. 1985; Schon, 1986) and latterly within CBT supervision (e.g. Bennett-Levy et al. 2009). 
Studies of therapist development have highlighted its vital role (e.g. Bennett-Levy et al. 2001, 2003; Milne \& James, 2002; Freeston et al. 2003). However, notwithstanding the importance placed on reflection, supervisees in the current study were unable to identify specific strategies which they used to aid their reflection, other than reflective writing (e.g. Bolton, 2005), via their supervision notes. At earlier stages, the supervisees' notes helped them to process the more pragmatic aspects of receipt. As their conceptual and technical skills developed, trainees reported a greater focus on procedural knowledge and interpersonal processes in therapy (Safran \& Segal, 1990; Bennett-Levy, 2006). Processing the receipt of interpersonal material had a gradual, experimental, and accidental quality about it.

Bennett-Levy (2006) stresses the significance of reflection in his DRP model and proposes that it is at later stages in the development of clinical expertise that tacit procedural skills are converted into declarative knowledge. The current study would certainly lend support for this proposition, but further work is required to explore the intricacies involved. One explanation is that because subtle dynamics are less likely to be made explicit; trainees may not be clear about what they are actually reflecting upon? For example, the supervisees described this as an implicit feeling state, rather than an explicit knowing state. Another explanation may be that interpersonal processes need to be applied before they begin to make sense. It may be that trainees did not explicitly bring interpersonal process material to supervision until later stages, because of a lack of ability to clearly articulate their needs. Arguably, this may be where videotapes of sessions are essential (Bennett-Levy \& Thwaites, 2009). While some trainees found it useful, it was not the norm for trainees, in the current study, to audio- or video-record their therapy sessions with clients. At earlier stages supervisors may not have forced this issue, due to higher levels of anxiety in trainees. Interestingly, Shepherd et al. (2009) have found support for the use of therapy recordings for supervision purposes. Further work examining the intricacies of why these recordings are helpful would be of use. There is some evidence that supervisees, in the current study, developed an ability to move from a position of 'reflecting on action' (i.e. after their supervision session) to a position of reflection in action (i.e. within supervision). This supports findings from previous research regarding the development of the reflective practitioner (e.g. Schon, 1986). Finally, 'meta-reflection' on overall supervision experiences across different placements was viewed, by supervisees in the current study, as a significant gap in their training.

\section{Limitations}

This study was restricted to supervisees from one course who were known to the researcher. While there is evidence that interviewees prefer to talk to people with whom they have established rapport (Kvale \& Brinkmann, 2008), it is acknowledged that this may have influenced some of the responses provided. This study did not test a model of supervision, but it may have been useful to specifically select trainees who were known to have been supervised by supervisors who had undertaken specialist training in one supervision model (e.g. CBT-based supervision).

\section{Implications for future research}

Cross-sectional or longitudinal research designs employing 'traditional' statistical approaches which aim to examine isolated aspects of supervision often fail to account for the inherent 
complexity involved (e.g. Ellis \& Ladany, 1997). However, it should be noted that there are positivist accounts which match the complexity of the present analysis, such as a systematic review conducted by Milne et al. (2008). Based on 24 empirical studies, they too recognized the interacting core processes and the developmental context. Indeed, Kolb's (1984) model anticipated the developmental complexity emphasized by the present study and by Milne $e t$ al. (2008). Therefore, the present study appears to be novel in stressing the role of awareness in guiding experiential learning, and in providing an elegant, relatively parsimonious model, based on an established constructionist methodology. It is also heartening that this approach yielded findings that essentially corroborate the conclusions of quantitative research. An alternative (positivistic) approach may be to utilize statistical approaches which are specifically designed to study complex interactions, e.g. multi-level modelling (University of Bristol, 2009), multi-dimensional scaling techniques (MDS; StatSoft Inc., 2009), or singlesubject designs.

The following reflections emerge from the use of GTM within the present study. First, it would be useful to study receipt processes with experienced supervisees (i.e. as continuing professional development), to explore the way in which receipt of supervision is processed at later developmental stages. Second, it would be useful to explore whether supervisees trained in particular theoretical approaches process the receipt of supervision in qualitatively different ways. Given the negative comments made by the present supervisees in relation to their psychodynamic supervision, it may be especially helpful to explore the receipt of supervision from those who elect to work psychodynamically. This may provide some insight into whether it was the imposition of the psychodynamic model at a particular stage of training, or the model itself, which is viewed as pedagogically problematic. Third, it would appear that there is a great deal of potential in the micro-analysis of processes involved in receipt. Video-recorded observations of live supervision sessions would be valuable to see what actually happens in practice. Further, investigating the role of multi-media in the receipt of supervision may also be helpful (i.e. by selecting supervisees who use audio and video recordings to aid their processing of receipt). Given that qualitative data analysis software (e.g. NVIVO) now facilitates the direct analysis of video-recorded material, this may offer a useful tool to progress research in micro-skills. Finally, using qualitative approaches to study other aspects of the fidelity framework may helpfully differentiate aspects of receipt which overlap with other fidelity components (e.g. enactment or generalization), which may help move our understanding towards a more complete model of supervision.

\section{Implications for practice}

The current study suggests that the developmental stage of the supervisee needs careful consideration in terms of the selection of supervisors. Given some of the negative experiences highlighted in the current study, it may be sensible to expose trainees to supervisors who have demonstrated an appropriate level of competency in supervision. This could involve attendance at accredited supervisor training (e.g. Milne, 2010). For safety reasons it may be prudent to ask new supervisors to: jointly supervise a minimum number of trainees before being permitted to be a lead or sole supervisor; ensure they are working within an established evidence-based pedagogic model of supervision (e.g. Milne, 2009); and to agree an explicit contract. Similarly, one could argue that it may be prudent to provide training to 
help supervisees to understand that they too have a responsibility for helping the relationship to work. Further, for continuing professional development for both parties, it may be useful to encourage digital recordings of supervision sessions.

\section{Conclusions}

The fidelity construct 'receipt' is highly complex and does not lend itself easily to quantification and measurement using traditional statistical approaches. However, the use of a GTM may have captured this complexity. Specifically, the current study suggests that receipt changes according to a supervisee's developmental stage and that this is influenced by four key constructs which allow learning to take place (Scaffolding, Socratic Information Exchange, Reflection, Supervisory Alliance). The use of GTM in the present study has both corroborated and further developed the broad conclusions about experiential learning from quantitative research (Milne, 2009), adding a fresh emphasis on the pivotal role of the supervisee's awareness as a determinant of learning within supervision. Further research using a similar methodology may illuminate the micro-skills involved and provide further explanation as to how the four core processes interact, contributing towards a sound model of CBT supervision to fill the theoretical vacuum.

\section{Acknowledgements}

We are grateful to the supervisees for their willingness to participate in the interviews and for sharing their understanding of supervision.

\section{Declaration of Interest}

None.

\section{Recommended follow-up reading}

Colquitt JA, LePine JA, Noe RA (2000). Toward an integrative theory of training motivation: a meta-analytic path analysis of twenty years of research Journal of Applied Psychology 85, 678707.

Milne D, James I (2005). Clinical supervision: 10 tests of the tandem model. Clinical Psychology Forum 151, 6-9.

Watkins CE (1995). Psychotherapy supervisor development: on musings, models, and metaphor. Journal of Psychotherapy Practice and Research 4, 150-158.

\section{References}

Amrhein PC (2004). How does motivational interviewing work? What client talk reveals. Journal of Cognitive Psychotherapy 18, 323-336.

Amrhein PC, Miller WR, Yahne CE, Palmer M, Fulcher L (2003). Client commitment language during motivational interviewing predicts drug use outcomes. Journal of Consulting and Clinical Psychology 71, 862-878.

Bandura A (1997). Self-efficacy: The Exercise of Control. New York: Freeman. 
Beinart H (2004). Models of supervision and the supervisory relationship and their evidence base. In: Supervision and Clinical Psychology: Theory, Practice and Perspectives (ed. I. Fleming and L. Steen), pp. 36-50. New York: Brunner-Routledge.

Bellg AJ, Borrelli B, Resnick B, Hecht J, Minicucci DS, Ory M, Ogedegbe G, Orwig D, Ernst D, Czajkowski S (2004) Enhancing treatment fidelity in health behavior change studies: Best practices and recommendations from the NIH behavior change consortium. Health Psychology 23, 443-451.

Bennett-Levy J (2006). Therapist skills: a cognitive model of their acquisition and refinement. Behavioral and Cognitive Psychotherapy 34, 57-78.

Bennett-Levy J, Lee N, Travers K, Pohlman S, Hamernik E (2003). Cognitive therapy from the inside: Enhancing therapist skills from practising what we preach. Behavioural and Cognitive Psychotherapy 31, 143-158.

Bennett-Levy J, McManus F, Westling BE, Fennell M (2009). Acquiring and refining CBT skills and competencies: Which training methods are perceived to be most effective? Behavioural and Cognitive Psychotherapy 37, 571-583.

Bennett-Levy J, Thwaites R (2009). Self and self reflection in the therapeutic relationship. In: The Therapeutic Relationship in the Cognitive-Behavioral Therapies (ed. P. Gilbert and R. L. Leahy), pp. 255-281. London: Routledge.

Bennett-Levy J, Turner F, Beaty T, Smith M, Patterson B, Farmer S (2001). The value of selfpractice of cognitive therapy techniques and self-reflection in the training of cognitive therapists. Behavioral and Cognitive Psychotherapy 29, 203-220.

Bernard JM, Goodyear RK (2004). Fundamentals of Clinical Supervision. Boston: Pearson.

Blackburn IM, James IA, Milne DL, Baker C, Standart SH, Garland A (2001). The revised Cognitive Therapy Scale (CTS-R): psychometric properties. Behavioural \& Cognitive Psychotherapy 29, 431-446.

Bolton G (2005). Reflective Practice, 2nd edn. London: Sage.

Bordin ES (1983). A working alliance model of supervision. Counseling Psychologist 11, $35-42$.

Boud D, Keogh R, Walker D (1985). Reflection: Turning Experience into Learning. New York: Kogan Page.

Bringer JD, Johnston LH, Brackenridge CH (2004). Maximizing transparency in a doctoral thesis: the complexities of writing about the use of QSR*NVIVO within a Grounded Theory study. Qualitative Research 4, 247-265.

Bringer JD, Johnston LH, Brackenridge CH (2006)a). Using computer-assisted qualitative data analysis software to develop a grounded theory project, Field Methods 18, 245-266.

Bringer JD, Johnston LH, Brackenridge CH (2006)b). Swimming coaches' perceptions of sexual exploitation in sport: a preliminary model of role conflict and role ambiguity. The Sport Psychologist 20, 469-475.

Bringer JD, Johnston LH, Brackenridge CH (2007). Maximizing transparency in a doctoral thesis: the complexities of writing about the use of QSR*NVIVO within a Grounded Theory study. In: Qualitative Research 2, Volume 4: Qualitative Data Analysis (ed. A. Bryman), pp. 63-84. London: Sage.

Centre for Investigative Psychology (2009). (http://www.i-psy.com/publications/publications_reading. php). Accessed 31 May 2009.

Charmaz K (2006). Constructing Grounded Theory: A Practical Guide through Qualitative Analysis. London: Sage.

Coyne IT (1997). Sampling in qualitative research. Purposeful and theoretical sampling; merging or clear boundaries? Journal of Advanced Nursing 26, 623-630.

Culloty T, Milne DL, Sheikh AI (2010). Evaluating the training of clinical supervisors: a pilot study using the fidelity framework. The Cognitive Behaviour Therapist 3, 132-144. 
Denzin NK, Lincoln YS (eds) (2008). Collecting and Interpreting Qualitative Materials, 3rd edn. London: Sage.

Dewald PA (1997). The process of supervision in psychoanalysis. In: Handbook of Psychotherapy Supervision (ed. C. E. Watkins), pp. 31-43. Chichester: Wiley

Ellis MV, Ladany N (1997). Inferences concerning supervisees and clients in clinical supervision: an integrative review. In: Handbook of Psychotherapy Supervision (ed. C. E. Watkins), pp. 447-507. New York: Wiley.

Ellis MV, Ladany N, Krengel M, Schult D (1996). Clinical supervision research from 1981 to 1993: A methodological critique. Journal of Counseling Psychology 43, 35-50.

Freeston MH, Armstrong P, Twaddle V (2003). Supervision: integrating practical skills with a conceptual framework [unpublished document]. Available from Newcastle Cognitive and Behavioural Therapies Centre, UK.

Glaser BG, Strauss AL (1967). The Discovery of Grounded Theory: Strategies for Qualitative Research. New York: Aldine de Gruyter.

Green D (2004). Organizing and evaluating supervisor training. In: Supervision and Clinical Psychology: Theory, Practice and Perspectives (ed. I. Fleming and L. Steen), pp. 93-107. New York: Brunner-Routledge.

Hart G (1982). The Process of Clinical Supervision. Baltimore, MD: University Park Press.

Hawkins P, Shohet R (2007). Supervision in the Helping Professions. Buckingham: Open University Press.

Holloway EL (1984). Outcome evaluation in supervision research. Counseling Psychology 12, 167-174.

Holloway EL (1995). Clinical Supervision: A Systems Approach. Sage: London.

Holloway EL, Neufeldt SA (1995). Supervision: its contribution to treatment efficacy. Journal of Consulting and Clinical Psychology 63, 207-213.

Hutchison AJ, Johnston LH, Breckon J (2010). Using QSR-NVivo to facilitate the development of a grounded theory project: an account of a worked example. International Journal of Social Research Methodology 13, 283-302.

James IA, Milne DL, Blackburn I-M, Armstrong P (2006). Conducting successful supervision: novel elements towards an integrative approach. Behavioural and Cognitive Psychotherapy 35, 191200.

James IA, Milne DL, Morse R (2008). Microskills of clinical supervision: Scaffolding skills. Journal of Cognitive Psychotherapy: An International Quarterly 22, 29-36.

Johnston LH, Breckon JD, Hutchison A (2009). Influencing health behavior: applying theory to practice. In: Physical Activity and Health Promotion (ed. L. Dugdill, D. Crone and R. Graham), pp. 21-42. Chichester: Wiley-Blackwell.

Johnston LH, Corban RM, Clarke P (1999). Multi-method approaches to the investigation of adherence issues within sport and exercise: qualitative and quantitative techniques. In: Adherence Issues in Exercise and Sport (ed. S. J. Bull), pp. 263-288. Chichester: John Wiley \& Sons.

Kirschner PA, Sweller J, Clark RE (2006). Why minimal guidance during instruction does not work: An analysis of the failure of constructivist, discovery, problem-based, experiential, and inquiry-based teaching, Educational Psychologist 41, 75-86.

Kolb DA (1984). Experiential Learning. New Jersey: Prentice-Hall.

Kvale S, Brinkmann S (2008). Inter Views: Learning the Craft of Qualitative Research Interview. London: Sage

Ladany N, Ellis MV, Friedlander ML (1999). The supervisory alliance, trainee self-efficacy, and satisfaction with supervision. Journal of Counseling and Development 77, 447-455.

Ladany N, Melincoff DS (1999). The nature of counselor non-disclosure. Counselor Education and Supervision 38, 161-176.

Miller WR, Rollnick S (1991) Motivational Interviewing: Preparing People for Change. New York: Guilford Press. 
Miller WR, Rollnick S (2002). Motivational Interviewing: Preparing People for Change, 2nd edn. New York: Guilford Press.

Milne DL (2006). Developing clinical supervision research through reasoned analogies with therapy. Clinical Psychology and Psychotherapy 13, 215-222.

Milne DL (2007). An empirical definition of clinical supervision. British Journal of Clinical Psychology 46, 437-447.

Milne DL (2008). CBT supervision: from reflexivity to specialization. Behavioural \& Cognitive Psychotherapy 36, 779-786.

Milne DL (2009). Evidence-Based Clinical Supervision. Chichester: BPS/Blackwell.

Milne DL (2010). Can we enhance the training of clinical supervisors? A national pilot study of an evidence-based approach. Clinical Psychology and Psychotherapy 17, 321-328.

Milne DL, Aylott H, Fitzpatrick H, Ellis MV (2008). How does clinical supervision work? Using a Best Evidence Synthesis approach to construct a basic model of supervision. The Clinical Supervisor 27, 170-190.

Milne DL, James I (2002). The observed impact of training on competence in clinical supervision. British Journal of Clinical Psychology 41, 55-72.

Milne DL, Pilkington J, Gracie J, James IA (2003). Transferring skills from supervision to therapy: a qualitative and quantitative $\mathrm{N}=1$ analysis. Behavioural and Cognitive Psychotherapy 31, 193202.

Milne DL, Reiser RP, Cliffe T, Raine R (2011). SAGE: preliminary evaluation of an instrument for observing competence in CBT supervision. The Cognitive Behaviour Therapist 4, 123138.

Padesky CA (1996). Developing cognitive therapist competency: teaching and supervision models. In: Frontiers of Cognitive Therapy (ed. P. M. Salkovskis), pp. 266-292). London: Guilford Press.

Palomo M, Beinart H, Cooper MJ (2010). Development and validation of the Supervisory Relationship Questionnaire (SRQ) in UK trainee clinical psychologists. British Journal of Clinical Psychology 49, 131-149.

Popper KR (1972). Conjectures and Refutations: The Growth of Scientific Knowledge. London: Routledge and Kegan Paul.

Pretorius WM (2006). Cognitive-behavioural supervision: recommended practice. Behavioural and Cognitive Psychotherapy 34, 413-420.

QSR International (2009). (http://www.qsrinternational.com/). Accessed 31 May 2009.

Richards L, Morse JM (2007). ReadME First for a User's Guide to Qualitative Methods. London: Sage.

Resnick B, Bellg AJ, Borrelli B, DeFrancesco C, Breger R, Hecht J, Sharp DL, Levesque C, Orwig D, Ernst D, Ogedegbe G, Czajkowski S (2005). Examples of implementation and evaluation of treatment fidelity in the BCC studies: where we are and where we need to go. Annals of Behavioural Medicine 29, 46-54.

Roth A, Pilling S (2008). The competence framework for supervision [unpublished document]. (http://www.ucl.ac.uk/clinical-psychology/CORE/supervision_framework.htm).

Ryan RM, Deci EL (2000). Self-determination theory and the facilitation of intrinsic motivation, social development, and well-being. American Psychologist 55, 68-78.

Safran JD, Segal ZV (1990). Interpersonal Process in Cognitive Therapy. New York, Guilford.

Scaife J (2001). Supervision in the Mental Health Professions: A Practitioner's Guide. Hove: BrunnerRoutledge.

Schon D (1986). Educating the Reflective Practitioner. San Francisco: Jossey-Bass.

Schwandt TA (2003). Three epistemological stances for qualitative inquiry: interpretivism, hermeneutics, and social constructionism. In: The Landscape of Qualitative Research: Theories and Issues, 2nd edn (ed. N. K. Denzin and Y S. Lincoln), pp. 292-331. London: Sage. 
Shepherd L, Salkovskis P, Morris M (2009). Recording therapy sessions: an evaluation of patient and therapist reported behaviors, attitudes and preferences. Behavioral and Cognitive Psychotherapy 37, 141-150.

StatSoft Inc. (2009). Multi-dimensional scaling (http://www.statsoft.com/textbook/stmulsca.html). Accessed 31 May 200.

Stoltenberg CD, Delworth U (1987). Supervising Counselors and Therapists. San Francisco: JosseyBass.

Stoltenberg CD, McNeil BW (1997). Clinical supervision from a developmental perspective: research and practice. In: Handbook of Psychotherapy Supervision (ed. C. E. Watkins), pp. 184-202. Chichester: Wiley

Townend M (2008). Clinical supervision in cognitive-behavioural psychotherapy: Development of a model for mental health nursing through grounded theory. Journal of Psychiatric and Mental Health Nursing 15, 328-339.

Townend M, Iannetta L, Freeston MH (2002). Clinical supervision in practice: a survey of UK cognitive behavioural psychotherapists accredited by the BABCP. Behavioural and Cognitive Psychotherapy, 30, 485-50.

University of Bristol (2009). Multilevel models (http://www.cmm.bristol.ac.uk/learningtraining/multilevel-models/index.shtml). Accessed 31 May 2009.

Vygotsky LS (1978). Mind in Society: The Development of Higher Psychological Processes. Cambridge, MA: Harvard University Press.

Wampold BE, Holloway EL (1997). Research and methods in supervision research. In: Handbook on Psychotherapy Supervision (ed. C. E. Watkins Jr.), pp. 11-27. New York: Wiley.

Watkins CE (ed.) (1997). Handbook of Psychotherapy Supervision. New York: Wiley.

Weaks D (2002). Unlocking the secrets of 'good supervision': a phenomenological exploration of experienced counsellors' perceptions of good supervision. Counseling and Psychotherapy Research 2, 33-39.

Webb A, Wheeler S (1998). How honest do counselors dare to be in the supervisory relationship? An exploratory study. British Journal of Guidance and Counseling 26, 509-524.

Worthen V, McNeil BW (1996). A phenomenological investigation of 'good' supervision events. Journal of Counseling Psychology 43, 25-34.

\section{Learning objectives}

After reading this paper the reader should be able to:

(1) List five reasons why a model matters.

(2) Summarize progress to date on developing a CBT supervision model.

(3) Describe the main themes of the CBT supervision model that are outlined in the present paper. 